\title{
Value of Albumin-Fibrinogen Ratio and CRP-Albumin Ratio as Predictor Marker of Disease Activity in Egyptian RA Patients, Correlated with Musculoskeletal Sonography
}

This article was published in the following Dove Press journal:

Open Access Rheumatology: Research and Reviews

\author{
Naglaa Afifi (iD) ${ }^{1,2}$ \\ Basma M Medhat (D) $^{3}$ \\ Amani Mohamed Abdel Ghani (iD) 4 \\ Hend Galal eldeen \\ Mohamed Ali Hassan (ID ${ }^{5}$ \\ Mervat E Behiry (iD ${ }^{2,6}$ \\ 'Internal Medicine and Rheumatology, \\ Faculty of Medicine, Ain Shams \\ University, Cairo, Egypt; ${ }^{2}$ Internal \\ Medicine, Armed Forces College of \\ Medicine (AFCM), Cairo, Egypt; \\ ${ }^{3}$ Rheumatology and Rehabilitation, \\ Faculty of Medicine, Cairo University, \\ Cairo, Egypt; ${ }^{4}$ Clinical Pathology, Faculty \\ of Medicine, Ain Shams University, Cairo, \\ Egypt; ${ }^{5}$ Radiodiagnosis, Faculty of \\ Medicine, Ain Shams University, Cairo, \\ Egypt; ${ }^{6}$ Internal Medicine, and \\ Rheumatology, Faculty of Medicine, Cairo \\ University, Cairo, Egypt
}

\begin{abstract}
Purpose: To evaluate the albumin-fibrinogen ratio (AFR) and C-reactive protein-albumin ratio (CAR) as inflammatory markers in rheumatoid arthritis (RA) and to investigate their association with disease activity correlating with musculoskeletal ultrasonographic findings. Patients and Methods: A total of 125 cases of RA patients were consecutively enrolled in a multicenter cross-sectional study compared to 100 healthy controls, all subjects were investigated for fibrinogen, albumin, CRP, erythrocyte sedimentation rate, AFR, and CAR measurements. Patients' disease activity was assessed by disease activity score (DAS28ESR), and they were subjected to high-frequency ultrasound both in greyscale and power Doppler.
\end{abstract}

Results: RA patients had lower AFR and higher CAR than those in the control group (P< $0.001)$. A positive correlation was demonstrated between CAR and DAS score $(r=0.589, P=$ 0.0001), whilst there was a precise negative correlation between AFR and DAS 28-ESR ( $\mathrm{r}=$ $-0.74, \mathrm{p}<0.001)$. ROC curve analyses revealed fibrinogen showed the best sensitivity $(92.1 \%$ ) for the area under the curve of 0.928 , at a criterion of 2.47 , while AFR has an area under the curve of 0.826 with sensitivity and specificity $(86.84 \%$ and $75 \%$, respectively) at cut-off value 1.46. Actively diseased patients had elevated CAR than those in remission (P $<0.001)$. Patients with synovial thickening and bone erosions had lower AFR than those without, CAR was higher in patients with power doppler changes than those without $(\mathrm{p}=0.015)$.

Conclusion: Higher CAR and lower AFR were expressed in active RA than those in remission. CAR and AFR could be useful markers of ongoing inflammation and joint affection detected by musculoskeletal ultrasonography.

Keywords: rheumatoid arthritis, albumin-fibrinogen ratio, C-reactive protein, inflammation, ultrasonography

\section{Introduction}

Rheumatoid arthritis (RA) is a chronic systemic disorder of immune etiology that affects mainly the joints, ${ }^{1}$ driven by the inflammatory process through the release of various cytokines with cellular recruitment, infiltration, and proliferation resulting in synovial and tissue inflammation with accrual destruction. ${ }^{2}$

Upon stimulation of the pro-inflammatory substances, liver cells are provoked to produce acute-phase proteins like C-reactive protein (CRP) with a decrease in
Correspondence: Naglaa Afifi

Giza 125II, Egypt

Tel +201100097599

Fax +202628884

Email dr.naglaaafifi@gmail.com 
albumin synthesis. ${ }^{3}$ Moreover, fibrinogen, which is a plasma protein produced by the liver, serves as an indicator of inflammatory processes at various levels. ${ }^{4}$

There is well-established evidence of albumin to fibrinogen ratio (AFR) and $\mathrm{C}$-reactive protein to albumin ratio (CAR) ratios as potential biomarkers reflecting the inflammatory status in subjects with malignancy ${ }^{5}$, besides they could be possible predictors for clinical response to different cancer-treating modalities. ${ }^{6,7}$ In addition to malignancy, some studies reported the adequate utility of them in expecting recanalization in patients with myocardial infarction. ${ }^{8}$

Patients with RA have expressed many types of inflammatory substances that play a pivotal role in the pathogenesis and are highly correlated to disease activity score $(\mathrm{DAS})^{9}$. There is a rising concern of finding an easy, reliable, and non-costly marker for systemic inflammation detection and disease activity for strict targeting treatment.

Albeit, the serum levels of C-reactive protein (CRP) and erythrocyte sedimentation rate (ESR) are two surrogate markers for inflammatory evaluation in rheumatic diseases, their sensitivity and specificity are questioned. ${ }^{10}$ From this setting, CAR and fibrinogen to albumin ratios have been considered as good biomarkers of disease activity in ankylosing spondylitis (AS) patients. ${ }^{10}$

AFR ratio had been reported to be increased in rheumatoid arthritis as an indicator of chronic inflammation, while the CAR ratio was reduced with a solid correlation with disease activity, ${ }^{11}$ yet the literature is scarce and infrequent.

Musculoskeletal ultrasound (MSUS) has been increasingly employed in early RA diagnosis as a complementary tool to a physical examination that is highly correlated to disease activity and response to therapy. ${ }^{12}$ Therefore, the purpose of this study is to investigate the inflammatory role of AFR and CAR in RA and to evaluate their association with disease activity verified by musculoskeletal ultrasonographic findings.

\section{Patients and Methods}

\section{Study Design and Sample Population}

A case-control study that included 125 RA Egyptian patients fulfilling the 2010 American College of Rheumatology (ACR)/European League Against Rheumatism classification criteria for $\mathrm{RA}^{13}$ were consecutively recruited from Rheumatology outpatient clinic at Ain Shams University and Cairo University hospital, who were compared with 100 healthy age- and sexmatched volunteers as a control group.
Juvenile-onset patients ( $\leq 18$ years) were excluded from the study; other exclusion criteria included factors that could potentially alter inflammatory markers' levels such as pregnancy, comorbidities as diabetes mellitus, hypertension, renal and/or hepatic dysfunction, malignancy, concurrent infection(s), surgery, trauma or hemorrhagic events, and/or other coexisting connective tissue diseases.

Informed written consents were obtained from all subjects participating in this study after the proper orientation of the study objectives. The study conforms to the 1995 Helsinki declaration and approved. The study protocol was treated confidentially corroborated to Helsinki declarations of biomedical ethics and approved by the research ethical committee, Faculty of medicine, Ain Shams University FWA000017585 (No: FMASU R 54/2020).

\section{Methods}

All enrolled RA patients were subjected to clinical assessment of disease activity using the disease activity score in 28 joints (DAS 28-ESR). ${ }^{14}$

The DAS 28-ESR score was developed and validated by the EULAR, calculated by using the number of tender and swollen joints, measured levels of Erythrocyte Sedimentation Rate (ESR), and the visual analog scale (VAS) rating. According to the DAS 28-ESR values, the studied patients were divided into two subgroups; the remission subgroup defined as DAS 28-ESR score less than 2.6, while those with a score $\geq 2.6$ had active disease.

\section{Laboratory Evaluation}

Erythrocyte sedimentation rate (ESR) in the first hour was estimated by Western method, serum CRP was quantified by immunoturbidimetry (Beckman Coulter) on AU 680 instrument. Serum albumin was measured by bromocresol green (Beckman Coulter) on AU 680. Plasma fibrinogen was quantified by Stago compact analyzer using the Clauss technique. Thus, Albumin to Fibrinogen (AFR) and CRP to Albumin (CAR) ratios were estimated. $\mathrm{CBC}$ was performed on Cell_Dyn Ruby autoanalyzer (Abbot). Liver and kidney function tests were done by using AU 4.0 autoanalyzer.

\section{Radiological Evaluation}

Logiq P7 ultrasound device (GE, USA) was used for musculoskeletal Ultrasound assessment of MCP joints, PIP joints, and wrist joints for synovitis in B Mode (gray-scale) (GS) and power Doppler (pD) Flow using Outcome Measures in Rheumatology (OMERACT) semiquantitative scale to determine effusion, synovial 
hypertrophy, or erosions. ${ }^{15}$ The probe was a linear highresolution probe 7.5-12 MHZ. Synovitis in the GS and $\mathrm{pD}$, as well as tenosynovitis in $\mathrm{pD}$, were scored semiquantitatively (0-3) where active synovitis if GS $\geq 2$ and $\mathrm{pD} \geq 1$. Radiological assessment was done by one observer (radiologist) who was blind to patients' clinical data.

\section{Statistical Analysis}

After data collection and check for completeness and logical consistency. Pre-coded data were entered into Microsoft Office Excel 2010. Data were then transferred to Statistical Package for the Social Sciences, version 21. All statistical analyses were performed using two-tailed tests and an alpha error of 0.05 . A p-value $<\_0.05$ was considered statistically significant. Simple descriptive statistics (median value and interquartile range) were used to summarize the normally distributed quantitative data, and frequencies categorical variables. Comparisons between groups were done using the Mann-Whitney test and Chi-square test. Spearman test was used for correlations. Receiver operating characteristic (ROC) curve analysis was carried out to test the diagnostic performance of a test or the accuracy of a test to discriminate diseased cases from normal cases. The results were presented in tables and figures.

\section{Results}

One hundred twenty-five RA patients were included. The mean (SD) age was 38.42 (8.07) years; of whom 100 were females. Most of the studied patients (73\%) had moderate disease activity assessed by the DAS28-ESR score with a mean (SD) of 5.4 (1.33). The data demonstrated significantly higher levels of fibrinogen and CRP in patients (4.15 (3.21-

Table I Demographic and Laboratory Characteristics of the Studied Subjects

\begin{tabular}{|c|c|c|c|c|c|}
\hline \multicolumn{3}{|c|}{ Parameters } & $\begin{array}{l}\text { RA Group } \\
N=125\end{array}$ & $\begin{array}{l}\text { Control Group } \\
N=100\end{array}$ & P-value \\
\hline \multicolumn{3}{|c|}{ Age in yrs Median (IQR) } & $37.5(31.5-46)$ & $32(29.0-36.0)$ & 0.221 \\
\hline \multirow[t]{2}{*}{ Sex } & \multicolumn{2}{|c|}{ Female (N\&\%) } & $100(80 \%)$ & $70(70 \%)$ & 0.745 \\
\hline & \multicolumn{2}{|c|}{ Male (N\& \%) } & $25(20 \%)$ & $30(30 \%)$ & \\
\hline \multicolumn{3}{|c|}{$\begin{array}{l}\text { Disease duration in yrs } \\
\text { Median (IQR) }\end{array}$} & $8(5-10)$ & & \\
\hline \multirow{4}{*}{\multicolumn{2}{|c|}{ Extra-articular Manifestations }} & Rheumatoid nodules & $5(4 \%)$ & & \\
\hline & & Sjogren syndrome & $32(25.6 \%)$ & & \\
\hline & & Vasculitis & 0 & & \\
\hline & & ILD & $16(12.8 \%)$ & & \\
\hline \multicolumn{3}{|c|}{ Tender joint range/Median (IQR) } & $0-23 /(4(I-8)$ & & \\
\hline \multicolumn{3}{|c|}{ Swollen joint range/Median (IQR) } & $0-20 /(2(I-5)$ & & \\
\hline \multicolumn{3}{|c|}{ DAS28-ESR Median (IQR) } & $5.3(4.6-6.1)$ & & \\
\hline \multicolumn{3}{|c|}{ Albumin (gm/dl) Median (IQR) } & $4(3.8-4.2)$ & $3.9(3.7-4.0)$ & 0.164 \\
\hline \multicolumn{3}{|c|}{ CRP $(\mathrm{mg} / \mathrm{dl})$ Median (IQR) } & $\mid 4(|| .75-24)$ & $8(6.0-10.0)$ & 0.038 \\
\hline \multicolumn{3}{|c|}{ Fibrinogen $(g / l)$ Median (IQR) } & $4.15(3.21-5.65)$ & $1.80(1.58 .0-2.10)$ & $<0.001$ \\
\hline \multicolumn{3}{|c|}{$\begin{array}{l}\text { Rheumatoid factor } \mathrm{IU} / \mathrm{mL} \\
\text { Median (IQR) }\end{array}$} & $44(30.1-64)$ & & \\
\hline \multicolumn{3}{|c|}{ ACPA IU/mL Median (IQR) } & $63(29-87.5)$ & & \\
\hline \multicolumn{3}{|c|}{ AFR Median (IQR) } & $0.94(0.74-1.08)$ & $2(1.8-2.4)$ & $<0.001$ \\
\hline \multicolumn{3}{|c|}{ CAR Median (IQR) } & $3.6(2.45-5.8)$ & $2.2(1.3-2.8)$ & 0.031 \\
\hline
\end{tabular}

Abbreviations: IQR, interquartile range; IU, international unit; ILD, interstitial lung disease; DAS, disease activity score; CRP, C-reactive protein; ACPA, anti-citrullinated protein antibodies; AFR, albumin/fibrinogen ratio; CAR, CRP/albumin ratio. 
Table 2 Comparison Between the Rheumatoid Arthritis Subgroups

\begin{tabular}{|c|c|c|c|}
\hline $\begin{array}{ll}\text { Parameters } & \text { Group }\end{array}$ & $\begin{array}{l}\text { Active Disease Subgroup } \\
\mathrm{N}=95\end{array}$ & $\begin{array}{l}\text { Remission Subgroup } \\
\mathbf{N}=\mathbf{3 0}\end{array}$ & P-value \\
\hline Age in year Median (IQR)* & $36.5(30.0-43.3)$ & $30(28.3-38.3)$ & 0.09 \\
\hline Rheumatoid nodules ( $\mathrm{N}, \%)$ & $4(4.21 \%)$ & $\mathrm{I}(3.33 \%)$ & 0.20 \\
\hline Sjogren syndrome (N, \%) & $22(23.15 \%)$ & $10(33.3 \%)$ & 0.44 \\
\hline ILD (N, \%) & $10(10.52 \%)$ & $6(20.0 \%)$ & 0.60 \\
\hline Disease duration in year & 7.3(4-9) & $8(5-10)$ & 0.88 \\
\hline DAS 28-ESR Median (IQR) & $4.95(3.63-5.65)$ & $2.3(2.1-2.4)$ & $<0.001$ \\
\hline Albumin (gm/dl) Median (IQR) & $4.0(3.8-4.2)$ & $3.95(3.8-4.18)$ & 0.72 \\
\hline CRP (mg/dl) Median (IQR) & $12.0(8.0-18.0)$ & $6.0(6.0-9.5)$ & $<0.001$ \\
\hline Fibrinogen (g/l) Median (IQR) & $3.55(3.0-4.6)$ & $2.25(1.99-2.45)$ & $<0.001$ \\
\hline AFR Median (IQR) & $1.05(0.86-1.37)$ & $1.86(1.41-1.96)$ & $<0.001$ \\
\hline CAR Median (IQR) & $3.15(1.68-5.25)$ & $1.6(1.5-2.5)$ & 0.031 \\
\hline \multicolumn{4}{|l|}{ Medications (N, \%) } \\
\hline Methotrexate & 76 (79\%) & $24(80 \%)$ & 0.06 \\
\hline Steroids & $22(23 \%)$ & $16(53 \%)$ & \\
\hline Leflunomide & $61(64.2 \%)$ & $20(66.6 \%)$ & \\
\hline$\alpha \mathrm{TNF}$ blockers & 9 (9.4\%) & $4(13.3 \%)$ & \\
\hline
\end{tabular}

Abbreviations: *IQR, interquartile range; ILD, interstitial lung disease; DAS, disease activity score; CRP, C-reactive protein; AFR, albumin/fibrinogen ratio; CAR, CRP/ albumin ratio; TNF, tumor necrosis factor.

Table 3 Correlation of Fibrinogen, AFR and CAR with Different Parameters

\begin{tabular}{|c|c|c|c|c|c|c|}
\hline \multirow[b]{2}{*}{ Parameters } & \multicolumn{2}{|c|}{ Fibrinogen } & \multicolumn{2}{|l|}{ AFR } & \multicolumn{2}{|l|}{ CAR } \\
\hline & R-value & P-value & R-value & P-value & R-value & P-value \\
\hline Age in yrs & 0.240 & 0.093 & -0.337 & 0.017 & 0.279 & 0.073 \\
\hline ESR $(\mathrm{mm} / \mathrm{hr})$ & 0.727 & $<0.001$ & -0.670 & $<0.001$ & 0.629 & $<0.001$ \\
\hline Albumin $(\mathrm{gm} / \mathrm{dl})$ & $-0.05 I$ & 0.725 & 0.215 & 0.133 & $-0.457-$ & 0.002 \\
\hline CRP (mg/dl) & 0.667 & $<0.001$ & -0.611 & $<0.001$ & 0.925 & $<0.001$ \\
\hline Fibrinogen $(g / l)$ & & & -0.846 & $<0.001$ & 0.643 & $<0.001$ \\
\hline $\mathrm{RF}(\mathrm{IU} / \mathrm{mL})$ & -0.091 & 0.529 & 0.221 & 0.160 & 0.175 & 0.223 \\
\hline $\mathrm{ACPA}(\mathrm{IU} / \mathrm{mL})$ & -0.154 & 0.286 & 0.194 & 0.217 & 0.171 & 0.236 \\
\hline AFR & -0.846 & $<0.001$ & & & -0.623 & $<0.001$ \\
\hline CAR & 0.643 & $<0.001$ & -0.623 & $<0.001$ & & \\
\hline DAS 28-ESR & 0.853 & $<0.001$ & -0.740 & $<0.001$ & 0.589 & $<0.001$ \\
\hline
\end{tabular}

Abbreviations: ESR, erythrocytic sedimentation rate; RF, rheumatoid factor; ACPA, anti-citrullinated protein antibodies; CRP, C-reactive protein; AFR, albumin/fibrinogen ratio; CAR, CRP/albumin ratio; DAS, disease activity score.

5.65) and $14(11.75-24))$ respectively, compared to control (1.80 (1.58.0-2.10) and $8(6.0-10.0))$ respectively. Patients had higher CAR and lower AFR than healthy controls with a statistically significant difference. The demographic, clinical, and laboratory data of the studied subjects are summarized in (Table 1). Of the participants, $80 \%$ were prescribed methotrexate, $30 \%$ on steroids, $65 \%$ were receiving leflunomide while $20 \%$ have received Anti-TNF blockers.

Herein, significantly higher levels of fibrinogen, CRP, ESR, and CAR were noticed in patients with active disease in comparison to the remission subgroup. In addition to lower levels of albumin and AFR with significant values as depicted in (Table 2). However, age and sex were comparable in both groups. There is no significant difference regarding the different medications.

In the current study, there were significant positive correlations between the DAS 28-ESR score and each of fibrinogen and CAR $(p<0.001)$. On the other hand, the DAS 28-ESR score was noticed to negatively correlate to AFR $(p<0.001)$. Nevertheless, these ratios were not correlated with either rheumatoid factor (RF) or anti-citrullinated protein antibodies (ACPA) titers (Table 3). 
Table 4 Relation of Inflammatory Markers with Different Sonographic Findings

\begin{tabular}{|c|c|c|c|c|}
\hline \multicolumn{2}{|c|}{ Sonographic Findings } & \multirow{2}{*}{$\begin{array}{l}\text { Fibrinogen }(\mathrm{g} / \mathrm{l}) \\
3.3(2.9-4.5) \\
2.45(2.2-3.5) \\
0.029\end{array}$} & \multirow{2}{*}{$\begin{array}{l}\text { AFR } \\
1.15(0.85-1.4) \\
1.86(1.15-1.93) \\
0.007\end{array}$} & \multirow{2}{*}{$\begin{array}{l}\text { CAR } \\
3.05(1.63-4.83) \\
1.5(1.4-4.28) \\
0.076\end{array}$} \\
\hline Synovial thickening & $\begin{array}{l}\text { With }(n=92) \\
\text { Without }(n=33) \\
\text { P-value }\end{array}$ & & & \\
\hline Bone erosions & $\begin{array}{l}\text { With }(n=38) \\
\text { Without }(n=87) \\
\text { P-value }\end{array}$ & $\begin{array}{l}3.7(2.99-4.7) \\
3.08(2.3-3.9) \\
0.03\end{array}$ & $\begin{array}{l}0.94(0.83-1.28) \\
1.3 I(0.95-1.86) \\
0.043\end{array}$ & $\begin{array}{l}3.1(1.6-5.9) \\
2.6(1.5-3.6) \\
0.191\end{array}$ \\
\hline $\begin{array}{l}\text { Power } \\
\text { Doppler } \\
\text { changes }\end{array}$ & $\begin{array}{l}\text { With }(n=60) \\
\text { Without }(n=65) \\
\text { P-value }\end{array}$ & $\begin{array}{l}3.85(2.99-5.23) \\
2.73(2.16-3.3) \\
0.002\end{array}$ & $\begin{array}{l}0.98(0.81-1.32) \\
1.39(1.16-1.86) \\
0.005\end{array}$ & $\begin{array}{l}3.6(1.55-6.0) \\
1.95(1.5-2.75) \\
0.015\end{array}$ \\
\hline
\end{tabular}

Abbreviations: AFR, albumin/fibrinogen ratio; CAR, CRP/albumin ratio.

Multiple linear regression test was done and revealed that AFR was found to be a significant independent predictor of disease activity score at $95.0 \%$ Confidence Interval $(-1.734$ to -0.392$)$ for B coefficient -0.336 ( $\mathrm{p}$-value 0.003).

Attempting to relate the inflammatory markers with the musculoskeletal sonographic findings, it was found that those with positive erosive changes and synovial thickening had a significantly higher level of fibrinogen and lower ARF than those without. While CAR was significantly higher in casese with PD changes compared to patients who had not(Table 4). Musculoskeletal ultrasound finding of one patient in the current study was demonstrated in Figure (1).

ROC curve analysis was performed to evaluate the discriminate validity of these ratios as predictors of RA disease activity. The highest AUC was that of fibrinogen (0.928), at a cut-off point of 2.47 , with highest sensitivity (92.1\%) and specificity of $73.3 \%$ with $95 \%$ CI $(0.854$ $1.00, \mathrm{P}<0.001)$. While AFR has area under curve of 0.826 with sensitivity and specificity $(86.84 \%$ and $75 \%$, respectively) at cut-off value 1.461 with $95 \%$ CI (42.8-94.5, $\mathrm{P}<0.001)$. CAR had less specificity (66.67) for the area under curve of 0.789 , at a criterion 1.66 and sensitivity (81.58\%) with 95\% CI (65.7-92.3), $\mathrm{P}=<0.001$ Figure (2).

\section{Discussion}

The current study was carried out to identify the impact of albumin to fibrinogen ratio (AFR) and C-reactive protein to albumin ratio (CAR) on RA patients and their association with disease activity. We have noted a marked increase of $\mathrm{C}$-reactive protein to albumin ratio (CAR) and decrease in (AFR) among active rheumatoid arthritis patients.
Rheumatoid arthritis is an incapacitating progressive articular disease that needs close monitoring and early detection of the disease activity for the early therapeutic intrusion to avoid joint damage. ${ }^{1,16}$ Increased CRP, fibrinogen, and ferritin as acute phase reactants is a prominent feature of autoimmune diseases such as RA which reflects the inflammatory state and complements activation mediated by pro-inflammatory interleukins notably, IL-6, thus resulting in joint damage and progressive radiological findings. ${ }^{17}$

The current study revealed raised fibrinogen, ESR, and CRP and reduced albumin among the rheumatoid arthritis patients compared to healthy control, and these findings are quite consistent with any inflammatory state. ${ }^{18-21}$

Although high fibrinogen, ESR and CRP levels have been implicated in chronic inflammation and proportionally correlated to the released cytokines and active arthritis as in RA, ${ }^{22,23}$ these single markers' performance could be influenced by various factors, thus constructed ratios of CAR and AFR can be used as convenient laboratory markers, which indirectly express the state of inflammation and disease activity. Several studies have shed the attraction towards the potential inflammatory impact of CAR and AFR in systemic illness, therefore these ratios have been frequently considered as outcomes predictor markers in various diseases. ${ }^{20,21}$

According to the DAS-ESR score, higher CAR and lower AFR were found to be in patients in active disease than those patients with remission. Also, CAR was positively correlated with CRP and ESR, and DAS score, whereas AFR showed inverse correlations with them. These findings are matching with previously reported by Yang et al who declared that AFR and 


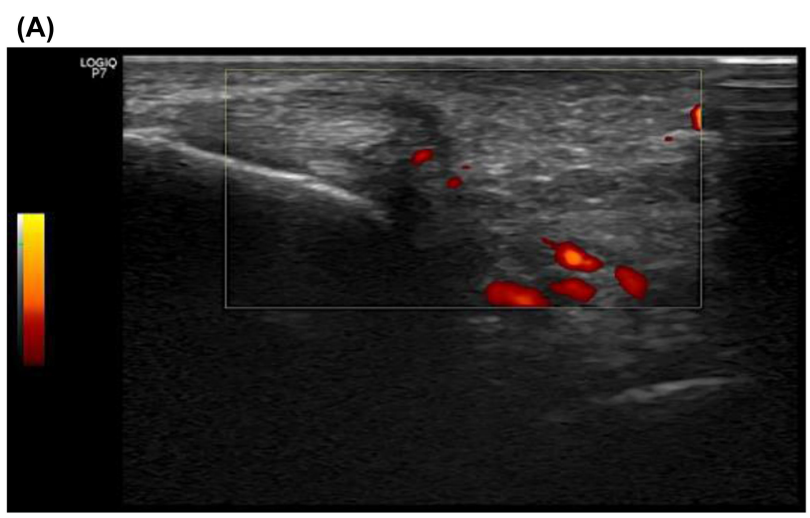

(B)

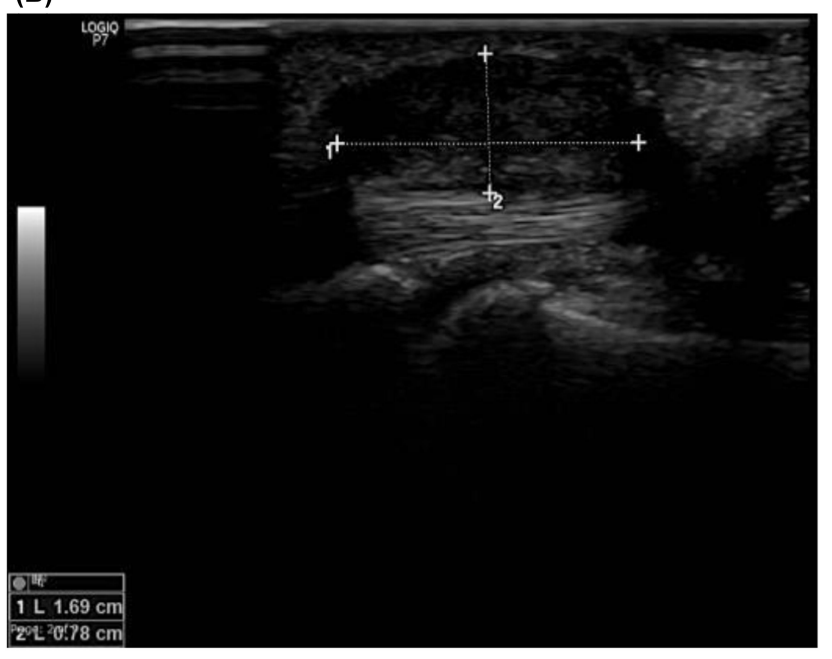

(C)

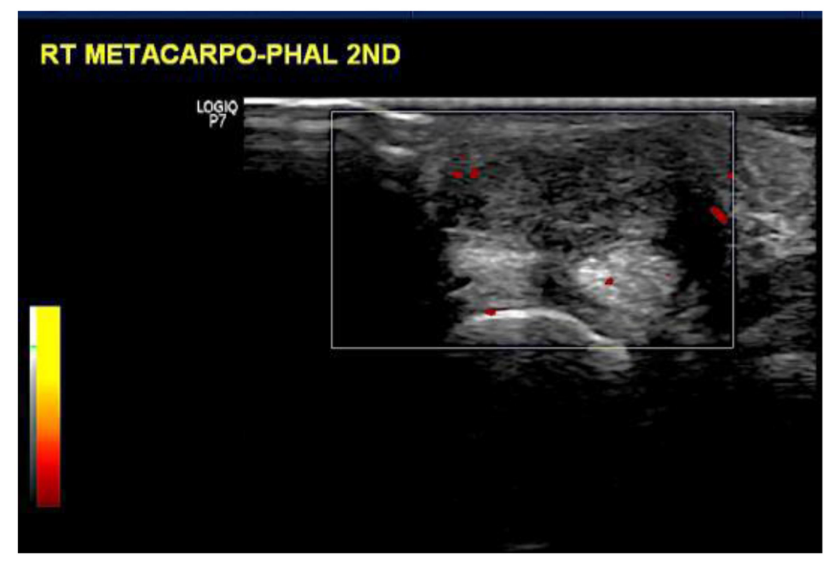

Figure I (AC) Musculoskeletal ultrasound finding of one patient in the current study. (A) longitudinal axis power Doppler US view of the palmar aspect of wrist joint shows increased joint space with hyperemia denoting synovial inflammation, (B) short-axis power Doppler US view (C) longitudinal axis grayscale US view of the volar aspect of 2nd Metacarpal pharyngeal Joint shows periarticular hyper-vascularization denoting synovitis with distention of the adjacent adventitial bursa measuring $1.6 \times 0.7 \mathrm{~cm}$.

CAR were correlated with DAS and CRP. Also, they could be simple predictors of disease activity in RA patients. $^{9}$

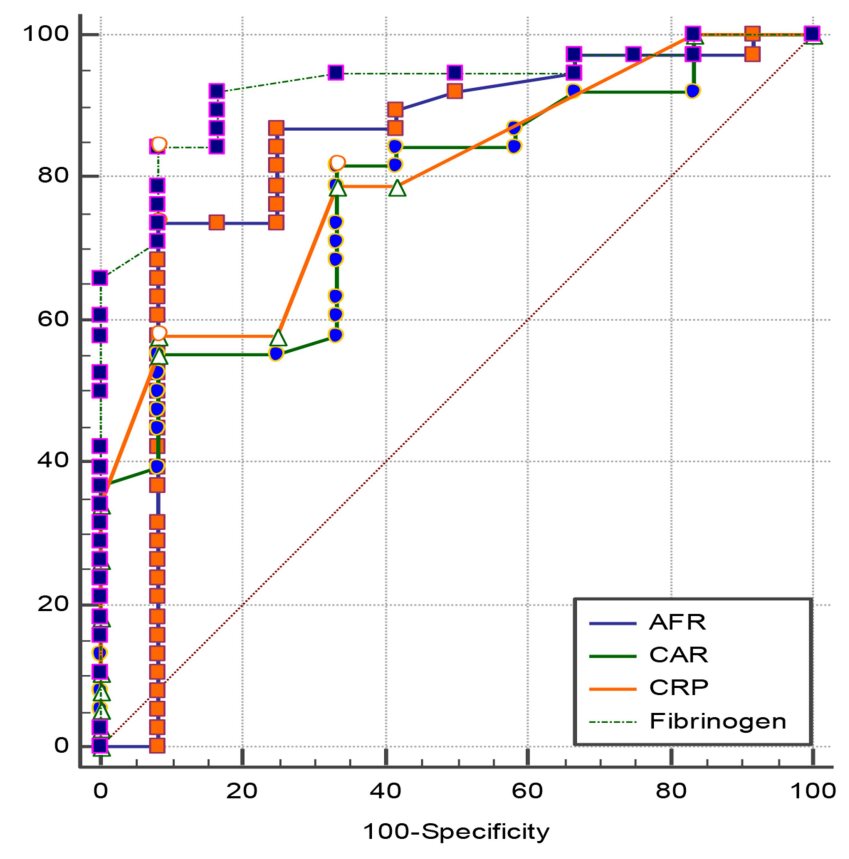

Figure 2 Roc curve analysis of the inflammatory markers for the prediction of RA disease activity.

Similarly, a recent study had demonstrated reduced AFR and raised CAR levels among the RA patients. Also, they noted that AFR and CAR were related to the inflammatory markers as CRP, ESR. ${ }^{11}$

Rheumatoid factor (RF) and anti-citrullinated protein antibodies (ACPA) are well described in RA. ${ }^{24}$ Albeit, it had been established that elevated titers of ACPA and RF are associated with increased disease activity and elevated ESR and CRP, ${ }^{25,26}$ their role in the pathogenesis of disease activity is not clearly understood. ${ }^{27,28}$ In the present study, there was no relation between AFR and CAR and the RF and ACPA levels. This is along with another study that revealed no relation between ratios and ACPA, but they are significantly correlated to RF concentrations. ${ }^{9}$

Sonography has been applied to the assessment of RA. Amplitude color doppler provides clinically useful information on synovial hyperemia which is a fundamental pathophysiologic feature of RA. ${ }^{29}$ Most likely, synovial hyperemia is believed to occur proportionally to joint-destructive disease activity, ${ }^{30}$ Ultra-sonography parameters of synovial disease relate strongly to DAS score as well as ESR and CRP in RA patients, ${ }^{31}$ it has been evident that doppler findings and CRP levels can reliably assess the disease activity and predict the progression of RA. ${ }^{32}$

In this study, it was found that patients with solid musculoskeletal sonar findings including synovial thickening, and 
bone erosions exhibited higher fibrinogen, and lower AFR than those without radiological findings with a significant difference. Moreover, CAR was considerably increased in patients with positive power doppler signals than those without. These data suggest the strong association of fibrinogen and AFR with RA outcome and joint damage while CAR could be a prognosticator of RA disease activity which is congruent with the previous studies. ${ }^{32}$

We evaluated the performance of CAR, AFR, and fibrinogen concentration to predict the disease activity. It has been observed that fibrinogen had better performance with higher sensitivity (92.1\%) upon which, we can rule out the suspected cases of active disease, while AFR showed better specificity (75\%); thus, active cases can be ruled in. Similarly, to our study, Yang et al had found AFR was an independent predictor for RA disease activity which indicates that the higher AFR may help to identify patients who are at risk of increased disease activity. ${ }^{9}$

It is worthy to point to the shortcomings of this work, the design of the study, with no follow up of the patients, we did not evaluate reliable inflammatory mediators such as TNF or interleukins to correlate adequately with those constructed ratios for more affirmative results. However, our study explores an area of inquiry not widely investigated in RA patients as well as the patients were collected from two centers giving considerable generalizability of data. We recommend further studies on larger scales and use of a structured model that constitutes of different scores and parameters to increase the accuracy of predicting RA disease activity.

\section{Conclusion}

RA patients exhibit significantly higher CAR and lower AFR than healthy subjects. CAR and AFR may be easily, rapidly detected and prognostically useful markers of ongoing inflammation and joint affection correspondingly to radiological findings. CAR has a better specificity as a reliable indicator of disease activity.

\section{Data Sharing Statement}

The datasets generated during and/or analyzed during the current study are available from the corresponding author on reasonable request.

\section{Acknowledgments}

We would like to thank all participants in this work.

\section{Funding}

This research did not receive any specific grant from funding agencies in the public, commercial, or not-forprofit sectors. The authors received no financial support for the research, authorship, or publication of this article.

\section{Disclosure}

The authors declare no potential conflicts of interest concerning the research, authorship, and/or publication of this article.

\section{References}

1. Chung SJ, Kwon YJ, Park MC, Park YB, Lee SKY. The correlation between increased serum concentrations of interleukin- 6 family cytokines and disease activity in rheumatoid arthritis patients. Med $J$. 2011;52(1):113-120.

2. Mervat EB. Sleep quality and fatigue in egyptian rheumatoid arthritis patients. Med J Cairo Univ. 2019;87(3):1557-1562. doi:10.21608/ mjcu.2019.53575

3. Shrivastava AK, Singh HV, Raizada A, et al. Inflammatory markers in patients with rheumatoid arthritis. Allergol Immunopathol. 2015;43 (1):81-87. doi:10.1016/j.aller.2013.11.003

4. Shrivastava AK, Pandey A. Inflammation and rheumatoid arthritis. $J$ Physiol Biochem. 2013;69(2):335-347. doi:10.1007/s13105-0120216-5

5. Sun D-W, Lin A, Guo Y. Albumin-fibrinogen ratio and fibrinogenprealbumin ratio as promising prognostic markers for cancers: an updated meta-analysis. World J Surg Onc. 2020;18:9. doi:10.1186/ s12957-020-1786-2

6. Lia S-Q, Jianga Y-H, Lin J, et al. Albumin-to- fibrinogen ratio as a promising biomarker to predict clinical outcome of non-small cell lung cancer individuals. Cancer Med. 2018;7(4):1221-1231. doi:10. $1002 / \mathrm{cam} 4.1428$

7. Tsujino T, Komura K, Hashimoto T, et al. C-reactive protein-albumin ratio as prognostic factor in renal cell carcinoma - A data from multiinstitutional study in Japan. Urol Oncol. 2019;37(11):812.e1812.e. doi:10.1016/j.urolonc.2019.04.002

8. Kayapinar O, Ozde C, Kaya A. Relationship between the reciprocal change in inflammation-related biomarkers (fibrinogen-to-albumin and hs-CRP-to-albumin ratios) and the presence and severity of coronary slow flow. Clin Appl Thromb Hemost. 2019;25:10 76029619835383. doi:10.1177/1076029619835383

9. Yang WM, Zhang WH, Ying HQ, et al. Two new inflammatory markers associated with disease activity score- 28 in patients with rheumatoid arthritis: albumin to fibrinogen ratio and C-reactive protein to albumin ratio. Int Immunopharmacol. 2018;62:293-298. doi:10.1016/j.intimp.2018.07.007

10. Liu M, Huang Y, Huang Z, et al. AB1326 increased fibrinogen to albumin ratio in ankylosing spondylitis: correlation with disease activity. Ann Rheum Dis. 2019;78:2126-2127.

11. He Y, Tang J, Wu B, Yang B, Ou Q, Lin J. Correlation between albumin to fibrinogen ratio, C-reactive protein to albumin ratio, and Th17 cells in patients with rheumatoid arthritis. Clinica Chimica Acta. 2020;500:149-154. doi:10.1016/j.cca.2019.10.009

12. Do Prado AD, Staub HL, Bisi MC, et al. Ultrasound and its clinical use in rheumatoid arthritis: where do we stand? Adv Rheumatol. 2018;58:19. doi:10.1186/s42358-018-0023-y

13. Aletaha D, Neogi T, Silman AJ, et al. Rheumatoid arthritis classification criteria: an American College of Rheumatology/European League Against Rheumatism collaborative initiative. Arthritis Rheum. 2010;62(9):2569-2581. doi:10.1002/art.27584 
14. Prevoo m L, Van 'T Hof MA, Kuper HH. Modified disease activity scores that include twenty-eight-joint counts. Development and validation in a prospective longitudinal study of patients with rheumatoid arthritis. Arthritis Rheum. 1995;38(1):44 48. doi:10.1002/art.1780380107

15. Wakefield RJ, Balint PV, Szkudlarek M, et al. Musculoskeletal ultrasound including definitions for ultrasonographic pathology. $J$ Rheumatol. 2005;32:2485-2487.

16. Singh HV, Shrivastava AK, Raizada A, et al. Atherogenic lipid profile and high sensitive C-reactive protein in patients with rheumatoid arthritis. Clin Biochem. 2013;46:1007-1012. doi:10.1016/j. clinbiochem.2013.03.023

17. Milman N, Karsh J, Booth RA. Correlation of a multi-cytokine panel with clinical disease activity in patients with rheumatoid arthritis. Clin Biochem. 2010;43:1309-14.32. doi:10.1016/j.clinbiochem.2010.07.012

18. Göbel K, Eichler S, Wiendl H, Chavakis T, Kleinschnitz C, Meuth SG. The coagulation factors fibrinogen, thrombin, and factor xii in inflammatory disorders-a systematic review. Front Immunol. 9:1731. doi:10.3389/fimmu.2018.01731

19. Raijmakers R, van Beers JJ, El-Azzouny M, et al. Elevated levels of fibrinogen-derived endogenous citrullinated peptides in synovial fluid of rheumatoid arthritis patients. Arthritis Res Ther. 2014;14(3):R114. doi:10.1186/ar3840

20. Tominaga T, Nonaka T, Sumida Y, Hidaka S, Sawai T, Nagayasu T. The C-reactive protein to albumin ratio as a predictor of severe side effects of adjuvant chemotherapy in stage III colorectal cancer patients. PLoS One. 2016;11(12):e0167967. doi:10.1371/journal.pone.0167967

21. Ishizuka M, Nagata H, Takagi K, Iwasaki Y, Shibuya N, Kubota K. Clinical significance of the $\mathrm{C}$-reactive protein to albumin ratio for survival after surgery for colorectal cancer, Ann. Surg Oncol. 2016;23(3):900-907. doi:10.1245/s10434-015-4948-7

22. Sahebari M, Ayati R, Mirzaei H, et al. Serum trace element concentrations in rheumatoid arthritis, Biol. Trace Elem Res. 2016;171 (2):237-245. doi:10.1007/s12011-015-0501-6

23. Beydoun HA, Archer DF, Zonderman AB, Beydoun MA. Interrelationships of sex, physician-diagnosed arthritis, chronic inflammation, and physical functioning in the third national health and nutrition examination surveys. Gerontol Geriatr Med. 2015;28 (1):2333721415591680.
24. Lee DM, Schur PH. Clinical utility of the anti-CCP assay in patients with rheumatic diseases. Ann Rheum Dis. 2003;62(9):870-874. doi:10.1136/ard.62.9.870

25. Hueber W, Utz PJ, Robinson WH. Autoantibodies in early arthritis: advances in diagnosis and prognostication. Clin Exp Rheumatol. 2003;21(5 Suppl 31):S59-64.

26. Miriovsky BJ, Michaud K, Thiele GM, et al. Anti-CCP antibody and rheumatoid factor concentrations predict greater disease activity in men with rheumatoid arthritis. Ann Rheum Dis. 2010;69:1292-1297. doi:10.1136/ard.2009.122739

27. Jeremy S, Dannette S, Lauren J, et al. Rheumatoid factor as a potentiator of anti-citrullinated protein antibody-mediated inflammation in rheumatoid arthritis. Arthritis Rheumatol. 2014;66(4):813821. doi:10.1002/art.38307

28. Shin YS, Choi JH, Nahm DH, Park HS, Cho JH, Suh CH. Rheumatoid factor is a marker of disease severity in Korean rheumatoid arthritis. Yonsei Med J. 2005;46(4):464-470. doi:10.3349/ ymj.2005.46.4.464

29. Snekhalatha U, Muthubhairavi V, Anburajan M, Gupta N. Ultrasound color doppler image segmentation and feature extraction in MCP and wrist region in evaluation of rheumatoid arthritis. J Med Syst. 2016;40(9):197. doi:10.1007/s10916-016-0552-z

30. Hammer HB, Kvien TK, Terslev L. Ultrasound of the hand is sufficient to detect subclinical inflammation in rheumatoid arthritis remission: a post hoc longitudinal study. Arthritis Res Ther. 2017;19 (1):221. doi:10.1186/s13075-017-1428-4

31. Fiocco U, Ferro F, Vezzu M, Cozzi L, Checchetto C, Sfriso P. Rheumatoid and psoriatic knee synovitis: clinical, greyscale, and power Doppler ultrasound assessment of the response to etanercept. Ann Rheum Dis. 2005;64(6):899-905. doi:10.1136/ard.2004.025585

32. Hameed B, Pilcher J, Heron C, Kiely PDW. The relation between composite ultrasound measures and the DAS28 score, its components, and acute phase markers in adult RA. Rheumatology. 2008;47(4):476-480. doi:10.1093/rheumatology/kem383
Open Access Rheumatology: Research and Reviews

\section{Publish your work in this journal}

Open Access Rheumatology Research and Reviews is an international, peer-reviewed, open access journal publishing original research, reports, editorials, reviews and commentaries on all aspects of clinical and experimental rheumatology in the clinic and laboratory including the following topics: Pathology, pathophysiology of rheumatological diseases; Investigation, treatment and management

\section{Dovepress}

of rheumatological diseases; Clinical trials and novel pharmacological approaches for the treatment of rheumatological disorders. The manuscript management system is completely online and includes a very quick and fair peer-review system, which is all easy to use. Visit http://www.dovepress.com/testimonials.php to read real quotes from published authors. 